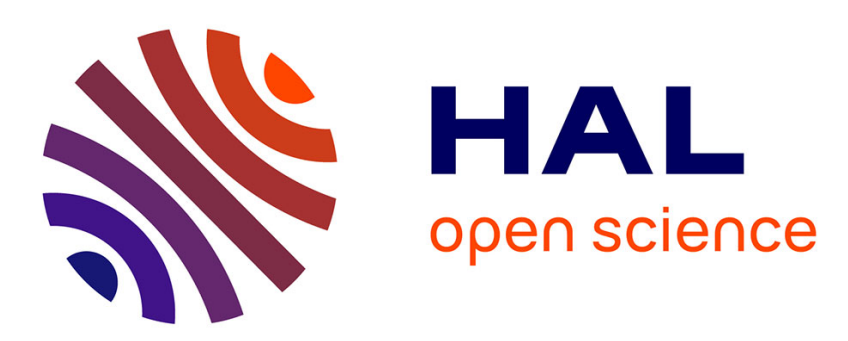

\title{
A ruptured cornual pregnancy successfully managed in a patient with a history of oophorectomy and salpingectomy: A rare case report
}

Marah Mansour, Amr Hamza, Alhomam Almarzook, Ilda Moafak Kanbour, Tamim Alsuliman, Bashar Kurdi

\section{To cite this version:}

Marah Mansour, Amr Hamza, Alhomam Almarzook, Ilda Moafak Kanbour, Tamim Alsuliman, et al.. A ruptured cornual pregnancy successfully managed in a patient with a history of oophorectomy and salpingectomy: A rare case report. Clinical Case Reports, 2021, 9 (10), 10.1002/ccr3.4934. hal-03405457

\section{HAL Id: hal-03405457 \\ https://hal.sorbonne-universite.fr/hal-03405457}

Submitted on 27 Oct 2021

HAL is a multi-disciplinary open access archive for the deposit and dissemination of scientific research documents, whether they are published or not. The documents may come from teaching and research institutions in France or abroad, or from public or private research centers.
L'archive ouverte pluridisciplinaire HAL, est destinée au dépôt et à la diffusion de documents scientifiques de niveau recherche, publiés ou non, émanant des établissements d'enseignement et de recherche français ou étrangers, des laboratoires publics ou privés. 


\title{
A ruptured cornual pregnancy successfully managed in a patient with a history of oophorectomy and salpingectomy: A rare case report
}

\author{
Marah Mansour $^{1}$ (D) | Amr Hamza A $^{2}$ AlHomam AlMarzook $^{3}$ | \\ Ilda moafak kanbour ${ }^{4}$ | Tamim Alsuliman ${ }^{5}$ | Bashar kurdi ${ }^{6}$ \\ ${ }^{1}$ Faculty of Medicine, Tartous University, Tartous, Syrian Arab Republic \\ ${ }^{2}$ Faculty of Medicine, Aleppo University, Aleppo, Syrian Arab Republic \\ ${ }^{3}$ Department of Neurosurgery, Ibn Al-Nafees Hospital, Damascus, Syrian Arab Republic \\ ${ }^{4}$ Department of Obstetrics and Gynecology, Maternity Hospital, Damascus, Syrian Arab Republic \\ ${ }^{5}$ Hematology and Cell Therapy Department, Saint-Antoine Hospital, AP-HP, Sorbonne University, Paris, France \\ ${ }^{6}$ Chair of Department of Obstetrics and Gynecology, Maternity Hospital, Damascus, Syrian Arab Republic
}

\section{Correspondence}

Marah Mansour, Faculty of Medicine, Tartous University, Tartous, Syrian Arab Republic.

Email: marahmohammad66@gmail. com

Funding information

No funding was required

\begin{abstract}
Cornual pregnancy is a rare condition that accounts for approximately $2-4 \%$ of ectopic pregnancies worldwide. Herein, we report an unstable case of a 32-year-old woman with a history of oophorectomy and salpingectomy who was admitted for a ruptured cornual pregnancy in the left cornu, which was successfully managed by laparotomy.
\end{abstract}

\section{K E Y W O R D S}

cornual pregnancy, ectopic pregnancy, exploratory laparotomy, pfannenstiel incision

\section{1 | INTRODUCTION}

Ectopic pregnancy is a common and potentially hazardous condition in which a viable ovum implants outside the uterine corpus. ${ }^{1}$ Cornual pregnancy $(\mathrm{CP})$ is considered the most troublesome sort of ectopic pregnancy due to low affectability, the explicitness of side effects, and imaging analyses. ${ }^{2} \mathrm{CP}$ is a rare entity in the general population, particularly in spontaneous pregnancies, and accounts for $2-4 \%$ of ectopic pregnancies. ${ }^{1,2}$ The exemplary triad of $\mathrm{CP}-$ stomach agony, amenorrhea, and vaginal dying-happens in under $40 \%$ of patients. $^{2}$ Transvaginal ultrasound and $\beta$-HCG are imperative for the early diagnosis of $\mathrm{CP}^{3}$ Ultrasonography should be used to establish CP management (particularly threedimensional ultrasonography). According to the size and viability of the pregnancy, the procedure should be planned. ${ }^{4}$ Laparotomy is typically used to manage $\mathrm{CP} .^{3}$ Adequate suturing of uterine cornua could preclude the risk of rupture during upcoming pregnancies. Decreased blood loss during and after the operation is a priority. ${ }^{4}$ Aside from surgical treatment, $\mathrm{CP}$ can also be managed 
conservatively by (systemic or local) methotrexate injections. Methotrexate therapy is typically ineffective in advanced cornual pregnancies with elevated $\beta$-HCG levels. ${ }^{1,3}$

\section{CASE PRESENTATION}

A 32-year-old woman, gravida 5, para 4, and aborta 1, presented to the Department of Obstetrics and Gynecology with severe lower abdominal pain that began approximately 1 day ago and had progressively worsened. The last menstrual period (LMP) was 40 days ago with a medical history of left Fallopian tube pregnancy a year ago, which was successfully managed by oophorectomy and salpingectomy of the left side. Previous pregnancies resulted in uncomplicated spontaneous vaginal deliveries. No history of tobacco, alcohol, allergies, or medications was reported. The vital signs were measured (blood pressure: 100/60 $\mathrm{mm} \mathrm{Hg}$, pulse rate: 110/min, and BMI:

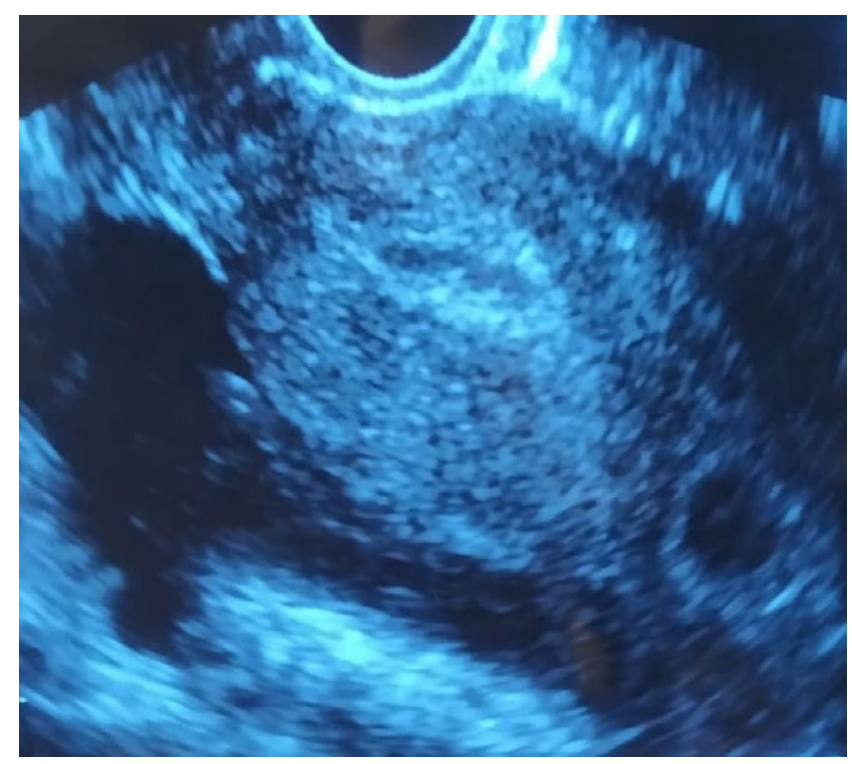

F I G U RE 1 Transvaginal two-dimensional ultrasonography scan in transverse view showing left interstitial ectopic pregnancy
$21 \mathrm{~kg} / \mathrm{m}^{2}$ ). Laboratory findings were as follows: hemoglobin: $10.3 \mathrm{~g} / \mathrm{DL}$, hematocrit: $28.1 \%$, leukocyte count: 20.5/ $\mu \mathrm{m}$, neutrophils: $90 \%$, and platelets: $357 / \mu \mathrm{m}, \beta$-HCG: $7503 \mathrm{IU} / \mathrm{L}$. Vaginal examination revealed a closed cervix with no vaginal bleeding, but tenderness to palpation and motion. Ultrasound demonstrated an empty uterus with decidual reaction, and a visible gestational sac located in the left cornu, the 5th-weeks' gestational sac in size (Figure 1), with a moderate amount of peritoneal fluid in Douglas Pouch extends to Morris pouch. An emergency exploratory laparotomy was performed via a Pfannenstiel incision. A ruptured gestational sac located in the left cornu was found, complicated by severe bleeding filling the peritoneal cavity, which was suctioned (Figure 2A,B). The products of conception, gestational sac, and left cornu were successfully eradicated (Figure 3A,B), (Figure 4). The $\mathrm{ZZ}$ drainage has been placed in Douglas's pouch and removed one week after surgery. One unit of blood was transfused during surgery. Pathological findings confirmed the diagnosis of ectopic pregnancy (Figure 4). The postoperative period was unremarkable; the patient was discharged $24 \mathrm{~h}$ after the surgery in a hemodynamically stable state. After 1 year of follow-up, there were no longterm complications. However, the patient uses oral contraceptives to prevent pregnancy.

\section{DISCUSSION AND CONCLUSION}

Cornual pregnancy is considered a rare entity that represents $2-4 \%$ of all tubal pregnancies. ${ }^{5}$ It could be a life-threatening condition as it tends to rupture in approximately $48.6 \%$ of cases, leading to potential consequences on the fetus and the female pregnant. ${ }^{6}$ Risk factors of CP include previous ectopic pregnancies, assisted reproductive techniques, tubal anomaly, proximal intra-tubal adhesions, and rarely ipsilateral salpingectomy. ${ }^{3,5}$ The symptoms usually occur 9 th to 12th weeks after the LMP due to myometrial stretchability. These include discomfort, abdominal pain, and

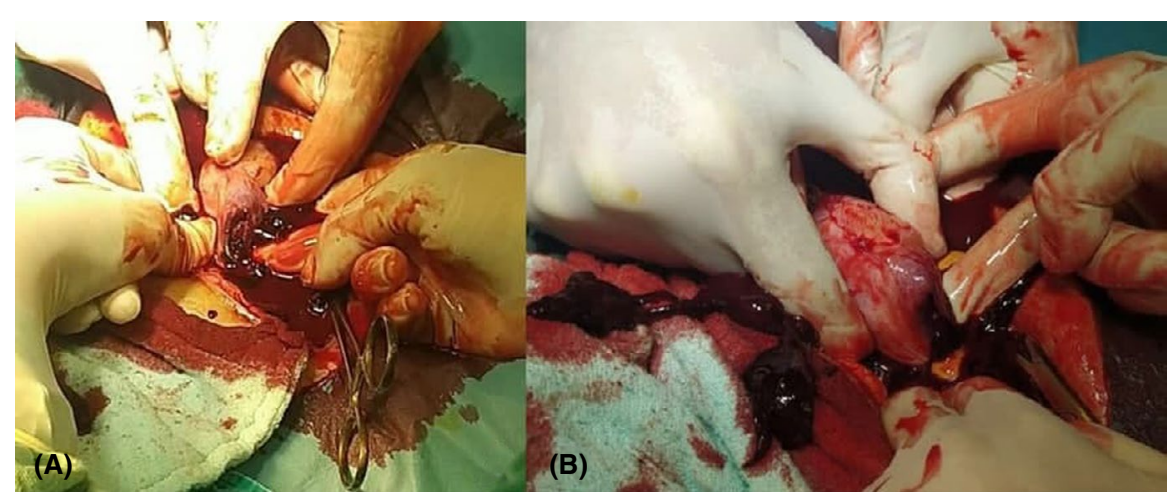

FI G URE 2 (A, B): View at the beginning of laparotomy findings showing a ruptured left uterine cornual ectopic pregnancy with showing the abdomen full of clots 
F I G U RE 3 (A, B): (A) Performing laparotomy cornual excisions. (B) The final result of surgery interrupted sutures

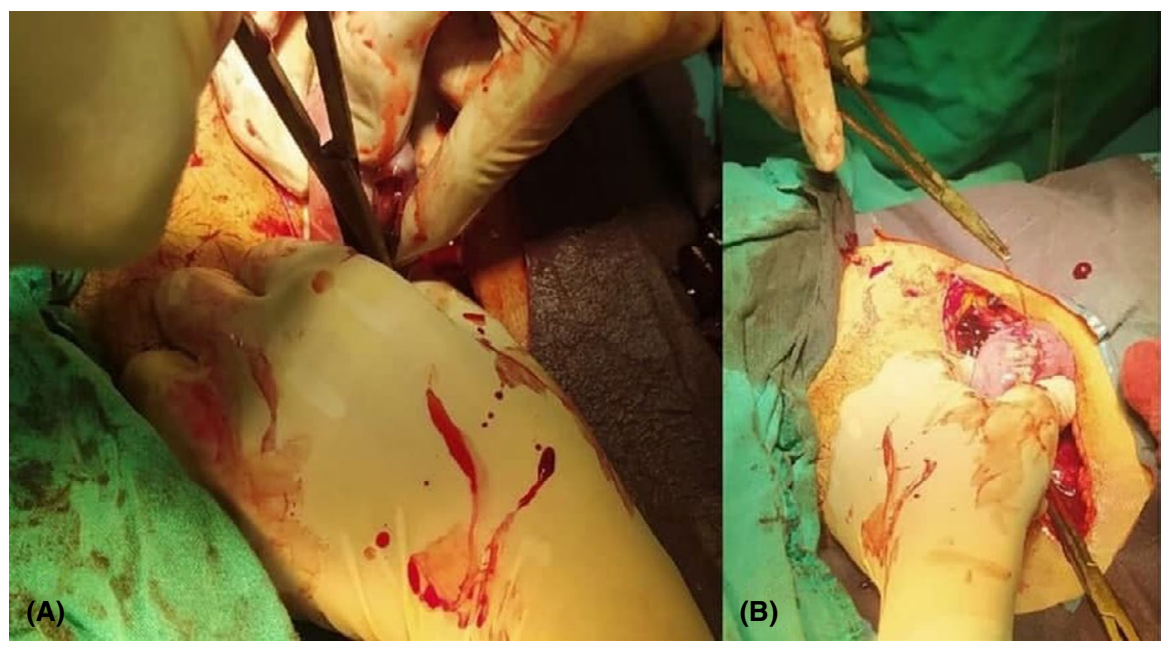

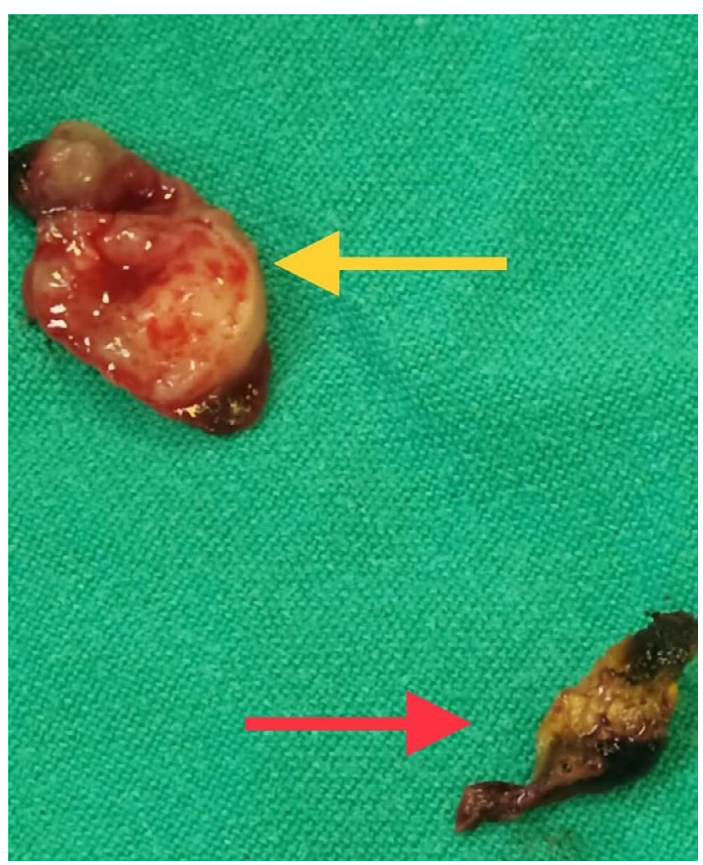

FI G URE 4 View showing the resection of the corneal (yellow arrow) with gestational sac (red arrow)

abnormal vaginal bleeding. ${ }^{7}$ Despite its complexity, early diagnosis of $\mathrm{CP}$ poses the cornerstone of lowering maternal mortality. Clinical features, increased $\beta-H C G$, and transvaginal ultrasonography are considered typical diagnostic modalities. ${ }^{4}$ However, ultrasonography could distinguish the gestational sac in uterine cornua with increased vascularity (Figure 1$){ }^{8}$ The literature reports a wide variety of treatment approaches. Previous interventions commonly included hysterectomy or cornual resection via laparotomy. However, more conservative laparoscopic approaches have been implemented recently, including cornual resection, cornustomy, and salpingectomy. ${ }^{5,9}$ Of interest, the potential persistent ectopic pregnancy has augmented after the conservative surgical procedures. However, rupture of CP could stimulate serious intra-abdominal bleeding resulting in hypovolemic shock; therefore, laparotomy could be preferred in hemodynamically unstable patients. ${ }^{4}$ Besides surgical treatment, $\mathrm{CP}$ can also be managed conservatively by (systemic or local) methotrexate injections. However, its adverse effects could include increasing $\beta$-HCG level, persistent abdominal pain, recurrent interstitial pregnancy, toxicity, and a risk of rupture in subsequent pregnancies. ${ }^{9}$ Furthermore, the local methotrexate injections appeared to be more efficient. ${ }^{6}$ The convenient decline in $\beta$-HCG blood level indicates successful management of a CP. ${ }^{10}$ Habana et al. discussed the outcomes of females undergoing surgery versus medical treatment, and the results revealed the advantages of surgery in terms of miscarriage ( $13 \%$ versus $50 \%, p<0.05)$ and live birth rate $(60.9 \%$ versus $50 \%))^{7,9}$ Spontaneous CP after ipsilateral salpingectomy is a very rare entity in which diagnosis is usually delayed. In conclusion, salpingectomy could not eliminate the potential of ipsilateral ectopic pregnancy. Therefore, an early well-organized follow-up of each pregnant with a history of salpingectomy is recommended to avoid potentially fatal consequences.

\section{ACKNOWLEDGMENT}

Not applicable.

\section{AUTHOR CONTRIBUTIONS}

Marah Mansour involved in design of study, data collection, data interpretation and analysis, drafting, critical revision, and approval of final manuscript. Amr Hamza involved in data collection, data interpretation and analysis, critical revision, drafting, and approval of final manuscript. AlHomam AlMarzook involved in data interpretation and analysis, critical revision, drafting, and approval of final manuscript. Ilda moafak kanbour involved in data collecting, critical revision, and approval of final manuscript. Tamim Alsuliman involved in drafting, critical revision, 
and approval of final manuscript. Bashar kurdi served as the Supervisor, involved in patient care, drafting, critical revision, and approval of final manuscript.

\section{ETHICAL APPROVAL}

Not required for this case report.

\section{CONSENT}

Written informed consent was obtained from the patient for publishing this case report and any accompanying images. A copy of the written consent is available for review by the Editor-in-Chief of this journal on request.

\section{DATA AVAILABILITY STATEMENT}

All data (of this patient) generated during this study are included in this published article and its supplementary information files.

\section{ORCID}

Marah Mansour (D) https://orcid. org/0000-0002-6129-5733

\section{REFERENCES}

1. Oral S, Akpak YK, Karaca N, Babacan A, Savan K. Cornual heterotopic pregnancy after bilateral salpingectomy and uterine septum resection resulting in term delivery of a healthy infant. Case Rep Obstet Gynecol. 2014;2014:157030. https://doi. org/10.1155/2014/157030. Epub 2014 Nov 5. PMID: 25431713; PMCID: PMC4238269.

2. Dagar M, Srivastava M, Ganguli I, Bhardwaj P, Sharma N, Chawla D. Interstitial and cornual ectopic pregnancy: conservative surgical and medical management. J Obstet Gynecol India. 2018;68(6):471-476. https://doi.org/10.1007/s13224-017-1078-0. Epub 2017 Nov 28. PMID: 30416274; PMCID: PMC6207538.
3. Maruthini D, Sharma V. A case of live birth after uterine reconstruction for recurrent cornual ectopic pregnancy following IVF treatment. Case Rep Obstet Gynecol. 2013;2013:1-6.

4. Pramayadi CT, Bramantyo A, Gunardi ER. Successful procedure in conservative management of interstitial (Cornual) ectopic pregnancy. Gynecol Minim Invasive Ther. 2018;7(4):172.

5. Tulandi T, Al-Jaroudi D. Interstitial pregnancy: Results generated from the society of reproductive surgeons registry. Obstet Gynecol. 2004;103:47-50.

6. Habana A, Dokras A, Giraldo JL, Jones EE. Cornual heterotopic pregnancy: contemporary management options. Am J Obstet Gynecol. 2000;182:1264-1270. https://doi.org/10.1067/ mob.2000.103620

7. Jourdain O, Fontanges M, Schiano A, Rauch F, Gonnet JM. Prise en charge des autres ectopies annexielles (cornuale, interstitielle, angulaire, ovarienne) [Management of other ectopic pregnancies (cornual, interstitial, angular, ovarian)]. J Gynecol Obstet Biol Reprod (Paris). 2003;32(7 Suppl):S93-S100.

8. Advincula AP, Senapati S. Interstitial pregnancy. Fertil Steril. 2004;82(6):1660-1661.

9. Moawad NS, Mahajan ST, Moniz MH, Taylor SE, Hurd WW. Current diagnosis and treatment of interstitial pregnancy. Am J Obstet Gynecol. 2010;202:15-29.

10. Zalel Y, Caspi B, Insler V. Expectant management of interstitial pregnancy. Ultrasound Obstet Gynecol. 1994;4:238-240.

How to cite this article: Mansour M, Hamza A, AlMarzook A, kanbour IM, Alsuliman T, kurdi B. A ruptured cornual pregnancy successfully managed in a patient with a history of oophorectomy and salpingectomy: A rare case report. Clin Case Rep. 2021;9:e04934. https://doi. org/10.1002/ccr3.4934 